\title{
Features of training IT specialists in the conditions of digital transformation of society
}

\author{
Alexander V. Boichenko \\ Plekhanov Russian University of Economics \\ Moscow, Russia \\ Boichenko46@mail.ru
}

\author{
Olga V. Lukinova \\ Institute of Control Sciences of Russian Academy of \\ Sciences \\ Moscow, Russia \\ Lobars@mail.ru
}

\begin{abstract}
Features of digital education when training IT specialists for digital economy are considered: what has caused digital transformation of education, substantial transformation, development of remote forms of education.
\end{abstract}

Keywords - digital economy, digital education, digital transformation, distance learning.

\section{INTRODUCTION}

Digital transformation of society begins. From approximately fifteen-year talk on post-industrial society, information society, society of knowledge the developed countries pass to implementation of digital transformation of all aspects of life of society. Russia also doesn't remain away from this process - are developed and claimed the Development strategy of information society in the Russian Federation for 2017-2030, the Digital Economy of the Russian Federation Program.

The Information and Communication Technologies (ICT) are the main instrument of digital transformation. Quickly changing requirements of the labor market, dying off of one professions, emergence of new impose requirements on fast adaptation to these processes of an education system and training. On the other hand education, as well as other fields of activity, for compliance to these requirements will be exposed to digital transformation, forming so-called digital education, understanding this term wide use of ICT in all aspects of educational process.

Thus, one may say, that the present stage of social development defines new requirements to education education through all life, improvement of quality and mass character of training for training of specialists, capable to work in the conditions of the developing digital economy.

The solution of problems of improvement of quality and mass character of training (to some extent contradicting each other) is impossible without widespread introduction in various levels and forms of education of modern methods and means of electronic training.

From the aforesaid it is possible to define the main objectives facing education informatization. It is transition from the simple accumulation of the computer equipment and communication opportunities used generally for the solution of organizational problems of training, to wide use of the intellectualized software (i.e. the best teachers bearing in themselves experience). It is creation of the highly professional electronic content reflecting the last scientific achievements, and presented in the electronic form which is most promoting easy and fast assimilation. It is creation of the computer means keeping development of practical skills. Besides, the modern electronic training aids shall include the last achievements in development of information and telecommunication technologies, first of all, it is technologies of cloud computing, use of methods and artificial intelligence techniques, achievements in the field of databases, data stores, knowledge bases.

The solution of these tasks is defined by the wide front of the international and Russian research and development, their approbation in practice.

Nevertheless, despite considerable progress in use of information technologies in education, it is possible to note a number of problems which require the solution. Use of technologies, innovations on their basis, aren't always supported with the corresponding pedagogical methodologies. If to consider the higher education as a key stage in training through all life on which there is a formation of the expert then it is possible to allocate a number of problems from the point of view of use at this stage of information technologies.

\section{FEATURES OF DIGITAL TRANSFORMATION OF THE MAIN ASPECTS OF A TRADITIONAL FORM OF RESIDENT INSTRUCTION}

The traditional form of resident not distance learning (face to face) from the point of view of formation of professional, moral and social competences contains a number of the directions of training.

\section{Directions of a training}

- Theoretical training (transfer of a certain volume of knowledge) the word "data" is plural, not singular.

- Practical training (seminars, laboratory works, practicians).

- Instilling of skills of research work irrespective of further, postgraduate specialization of the student (participation in research projects and student scientific circles, writing articles, papers, participation in conferences). 
- Character building, physical training.

- Development of innovative skills and thinking (ability to form innovative projects, startups, training of innovative activity in the conditions of modern market economy, economy of knowledge).

Development and use of electronic technologies isn't identical to remote realization of these aspects of preparation now.

The greatest advance can be noted regarding theoretical preparation - are created and function various LMS and LCMS, electronic training courses, means of communication. The main vector of development in this direction can be considered intellectualization of content, from the point of view of the best digestion of independently studied material, LMS, from the point of view of individual trajectories of studying both separate disciplines, and all program of training, use in LMS of the formalized experience of the best teachers when the teacher not only fixes result of training through control actions, but also explains to the student why from receives this or that assessment that he has missed in the course of training.

Realization of this aspect of preparation can give the chance to significantly exempt teachers from lecture work, having allowed them to focus on scientific work, entering of results of scientific work into the taught disciplines, involvement of students in scientific work.

Use of the Internet, various databases also imposes the specifics in work of the teacher and student at traditional fulltime courses. he role of the teacher in these conditions shouldn't comes down to the round-the-clock readiness to answer questions of each student. The teacher has to itself well to be guided in information which is in the Internet on the studied discipline to understand tendencies of development and application of this field of knowledge and, the main thing, to be able to arm the student with critical thinking which will allow to estimate information which is independently found the student correctly.

Remote practical preparation by means of information technologies assumes, first of all, existence for a wide range of disciplines, especially in the field of natural-science and technical disciplines, existence of virtual laboratories, the virtual equipment, various simulators, the systems of virtual reality. This direction is at the initial stage of the development.

Ehe third aspect of preparation - skills of research work also demands the development. Decisions in this direction have to be a part of the high school system supporting scientific activity of all higher education institution. Now in the market there is a number of the information systems offering various aspects of support of scientific activity, but, as a rule, they don't contain decisions on support of remote collective work on the project.

Regarding character building, instilling of skills of a healthy lifestyle application of electronic technologies for remote realization of this aspect is found at zero level. There are no scientific and methodical studies of these questions which could set requirements to the appropriate information technologies.

Need of development in specialists of innovative skills and thinking is declared by all strategic documents in the field of education today. Decisions regarding remote implementation of these requirements also demand the development. From the theoretical point of view these decisions can rely on success achieved in realization on the basis of information technologies regarding theoretical, practical and scientific training of students.

Summarizing the aforesaid it is possible to note the following. Achievement of the goal of mass and high-quality training of specialists, the competences possessing a full range which are provided by modern higher education institution has to lean on careful researches, formalization and realization in the form of information technologies of all aspects of preparation considered above. Additional professional education can use separate combinations of these aspects.

\section{TRANSFORMATION OF SUBSTANTIAL ASPECT OF TRAINING OF IT SPECIALISTS}

By training IT specialists for digital economy for ensuring bigger unification of processes of digital transformation more accurate differentiation on three directions - specialists in business processes (the general questions of the description of business processes, formalization and optimization of business processes, information processes), specialists in adaptation of business processes and information processes in applied areas, specialists in program and system engineering can be presented expedient.

From the point of view of a substantial part of preparation for all these directions, except basic courses, creation of special courses (or their display basically) on the new, developing information and communication technologies is represented expedient. It would be possible to take annually updated schedules of a cycle of a maturity as a basis of such courses of the appearing and developing information technologies and their description of Gartner.

\section{Such cycle of a maturity of ICT for 2016 is given in Fig. 1}

\section{TRAINING PROCESS TRANSFORMATION}

Other aspect of preparation of IT shots is connected with digital transformation of the branch of education. In this direction except the huge existing reserve in the field of remote forms of education, electronization of content, information management systems by higher education institution and process of training, the intellectualization of electronic forms of education reproducing experience of good teachers is represented to the most perspective.

This aspect is connected with automated management of process of training, and in a format, individual for the trainee. The main vector of development in this direction can be considered intellectualization of content from the point of view of definition of individual trajectories of studying, both separate disciplines, and all program of training, control of digestion of independently studied material, the formalized experience of the best teachers when the teacher not only fixes 
result of training through control actions, but also explains to the student why from receives this or that assessment that he has missed in the course of training.

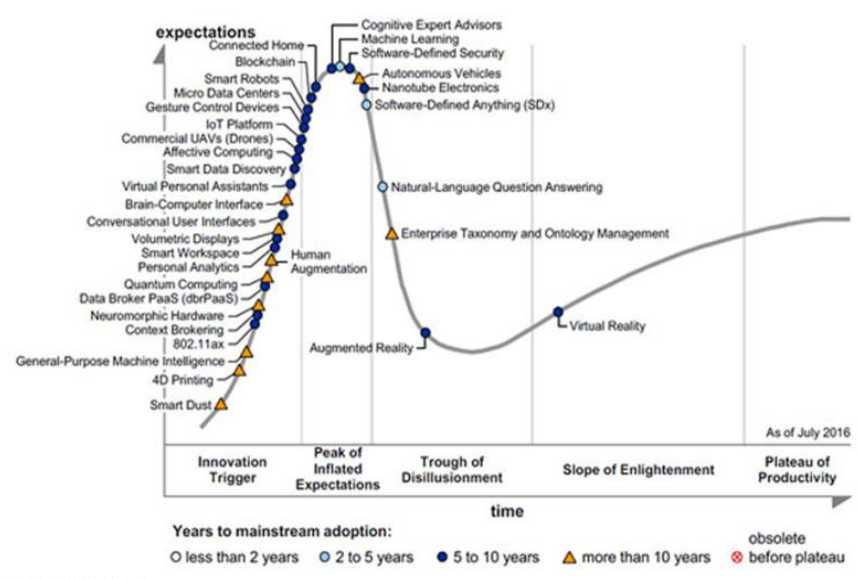

Fig. 1. Cycle of a maturity of information technologies of Gartner (Hype cycle for emerging technologies 2016, Gartner).

In this part are already created and various control systems of educational process of Learning Management System (LMS) which give the chance to each student to obtain the personified information on the individual curriculum, progress (the electronic record book) and the individual schedule, to independently plan the educational trajectory, delivery of projects and homeworks function; to the teacher - placements of materials for occupations, maintaining the working sheet, exchange of messages with students, testings of knowledge of students. Besides, the system carries out such administrative and analytical actions as generation of reports and data for the management and other ERP systems.

For management of educational content there are Learning Content Management System (LCMS) systems which, besides functions of control of knowledge, group work, provide to users (teachers and students) of a tools for training materials and also support of dynamic preliminary testing and adaptive training.

Besides, the analysis and introduction in digital formation of new standards and technologies in the field of electronic training, for example, presented in Fig. 2 are advisable.

Except technologies and the directions, more general and traditional for electronic training, at Fig. 2 it is possible to allocate two - xAPI and IMS Caliper.

xAPI (called also Tin Can, Experience API) is the specification of programs in the sphere of distance learning which allows the training systems to communicate among themselves by tracking and record of studies of all types. Information on educational activity is saved in special base storage of educational records (learning record store, LRS). LRS can be as a part of system of distance learning (LMS), well independent system.

Features of xAPI are:
- xAPI - the improved version of the SCORM specification.

- $\quad$ XAPI allows to write down any experience of training that gives us fuller picture of training of the specific person.

- xAPI lifts the limits imposed by the system of distance learning from data.

- XAPI is capable to render the invaluable help to educational departments, comparing data on quality of performance of work with educational data, that increasing learning efficiency.

\section{7 eLearning Predictions Hype Gurve}

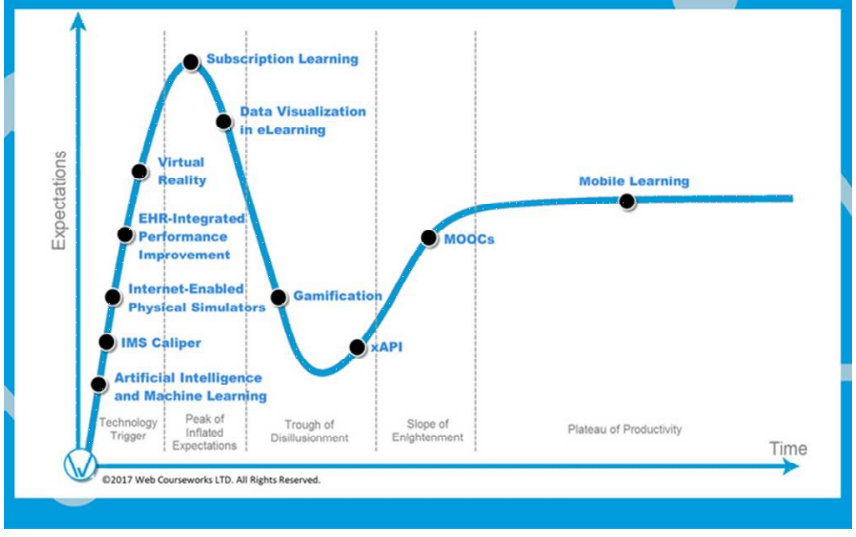

Fig. 2. A cycle (curve) of a maturity of the standards and technologies assumed to use in the field of electronic learning [5].

The xAPI specification is developed within the The Advanced Distributed Learning program (ADL) Initiative.

Caliper Analytics specification of consortium IMS Global Learning Consortium Inc. allows to collect, to store and transfer data on training process. As the base for analytics of Caliper provides the general platform for use and division of data on student's interactions in various applications used for training and learning management systems.

These two specifications are basic for analytics of interactions in the course of distance learning.

\section{CONCLUSION}

Thus, in conclusion it is possible to tell that preparation of IT shots for digital economy is on the threshold of big transformation. This transformation demands deep multidisciplinary judgment as in a substantial part, so in digital, first of all, intellectual transformation of forms of education and applications of new standards and technologies for the organization and management of processes of electronic training. 


\section{REFERENCES}

[1] Program "Digital Economy of the Russian Federation", http://static.government.ru/media/files/9gFM4FHj4PsB79I5v7yLVuPgu 4bvR7M0.pdf.

[2] The development strategy of information society in the Russian Federation,

http://static.government.ru/media/files/9gFM4FHj4PsB79I5v7yLVuPgu 4bvR7M0.pdf

[3] Functional structure of a control system of implementation of the "Digital Economy of the Russian Federation", http://static.government.ru/media/files/zutOPH6TyKz2ciJAFcn74orvpb 89UCMa.pdf

[4] Boichenko A.V., Causes and features of information society. Scientific notes of Institute of social and humanitarian knowledge. Release №. 1 (14). Kazan.2016.

[5] 2017 eLearning predictions: updated hype curve, http://www.webcourseworks.com/2017-elearning-predictions/ 